This item was submitted to Loughborough's Research Repository by the author.

Items in Figshare are protected by copyright, with all rights reserved, unless otherwise indicated.

\title{
Optimisation of AWD off-road vehicle performance using visco-lock devices
}

PLEASE CITE THE PUBLISHED VERSION

http://dx.doi.org/10.1504/IJHVS.2008.022242

\section{PUBLISHER}

(C) Inderscience Enterprises Ltd.

\section{VERSION}

SMUR (Submitted Manuscript Under Review)

\section{LICENCE}

CC BY-NC-ND 4.0

\section{REPOSITORY RECORD}

Sharaf, Al-Hossein M., George Mavros, Homer Rahnejat, P.D. King, and S.K. Mohan. 2014. "Optimisation of AWD Off-road Vehicle Performance Using Visco-lock Devices". figshare. https://hdl.handle.net/2134/14757. 
This item was submitted to Loughborough's Institutional Repository (https://dspace.lboro.ac.uk/) by the author and is made available under the following Creative Commons Licence conditions.

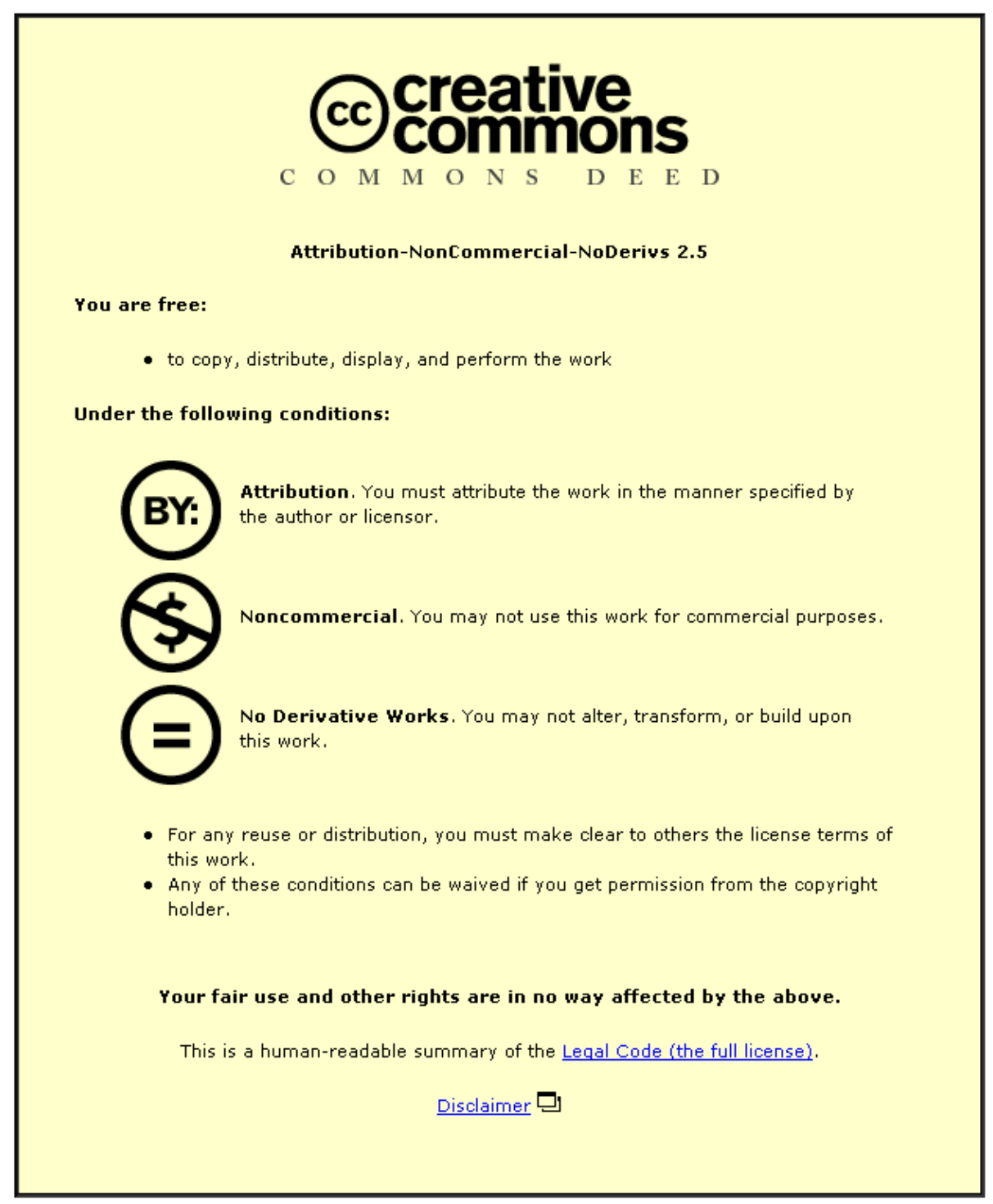

For the full text of this licence, please go to: http://creativecommons.org/licenses/by-nc-nd/2.5/ 


\title{
OPTIMIZATION OF AWD OFF-ROAD VEHICLE PEROFRMANCE USING VISCO-LOCK DEVICES
}

\author{
A.M. Sharaf ${ }^{1}$, G. Mavros ${ }^{2}$, H. Rahnejat ${ }^{1}$, P.D. King $^{1}$ and S.K. Mohan ${ }^{3}$
}

\begin{abstract}
A comprehensive computer model is devised for the simulation of AWD off-road vehicle dynamics. A full drivetrain system including all aspects of rotational inertial dynamics, friction, damping and stiffness properties are integrated within a fourteen-degrees-of-freedom vehicle model. For off-road simulations the terra-mechanical phenomena between tyres and deformable soils has also been taken into account. Simulations include viscolock devices, as well as conventional mechanical torque distribution systems. The interaction between all the aforementioned aspects is implemented in the MATLAB/SIMULINK/SimDriveline environment.

Particular attention has been paid to the modelling of various visco-lock devices, including the viscous couplings of shafts and visco-lock limited-slip differentials. The selection and tuning of such devices is usually based on a trial and error approach, which is time consuming and expensive. In the present work, these devices are represented by fully parameterised physical models which capture the torque transmission mechanism represented by various thermodynamic, hydrodynamic, structural and mechanical modules. The characteristics of these devices can easily be altered so that comparisons can be made between different types. In addition, the influence of a wide range operating conditions, vehicle design parameters and tyre characteristics can also be made over various deformable soils. Both viscous shear and self-torque amplification (hump) have been considered. The viscous fluid is considered to be non-Newtonian with appropriate shear rate and temperature dependent characteristics.
\end{abstract}

Keywords: 4x4 off-road vehicles, terramechanics, AWD vehicle performance, vehicle modelling.

\footnotetext{
${ }^{1}$ Wolfson School of Mechanical and Manufacturing Engineering, Loughborough University, Loughborough, Leicestershire, UK, LE11 3TU

${ }^{2}$ Department of Aeronautical and Automotive Engineering, Loughborough University, Loughborough, Leicestershire, UK, LE11 3TU

${ }^{3}$ Magna Powertrain, 6600 New Venture Gear Drive, East Syracuse, NY 13057-1209 USA
} 
Nomenclature:

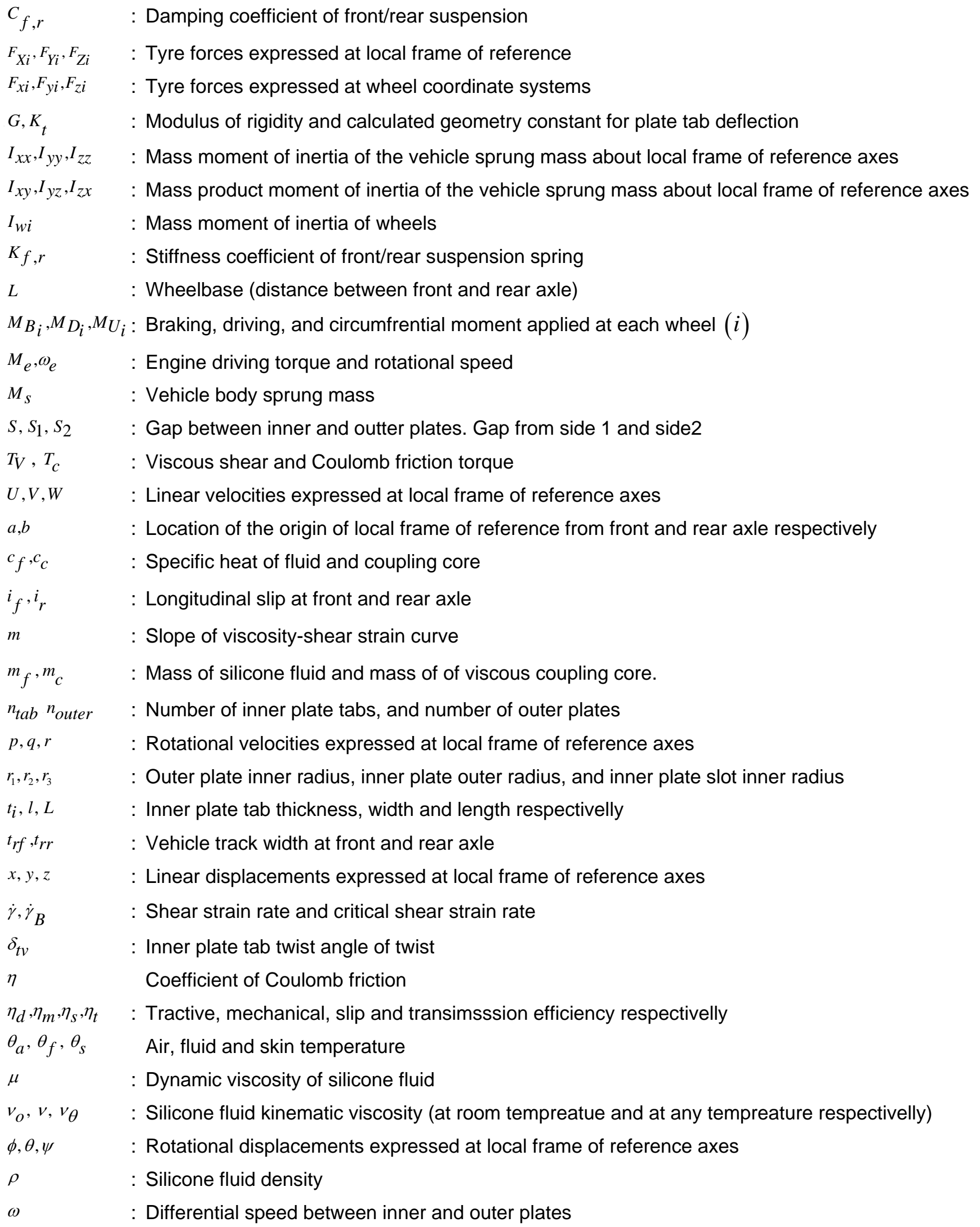




\section{Introduction}

Until 1980s 4WD was almost exclusively used for off-road vehicles. Today, nearly every American, European and Japanese vehicle manufacturer runs a special program for AWD vehicles. Systems used range from manual second axles through to computer controlled traction systems (Mohan and Williams, 1995). The rapidly increasing applications of AWD, particularly in the passenger vehicle sector demands the development of vehicles, not only with higher traction and acceleration capabilities, but also with better manoeuverability over deformable soil. Although improving traction performance is a main consideration for off-road vehicle applications, handling behaviour is an important aspect of modern vehicles, which requires capability to undergo high lateral accelerations, whilst maintaining good level of directional stability. The desired increase in mobility must be reached without making any compromises regarding safety or ease of operation or driver comfort. Consequently, optimisation between traction performance and lateral stability has become a complex task.

A peculiarity of AWD off-road vehicles is that their handling performance not only depends on the total tractive effort, but also on torque distribution between the driving wheels. Over the years a considerable volume of research has been carried out to investigate $4 \times 4$ vehicle behaviour fitted with different drivetrain configurations, (Maretzke and Richter, 1986; Tani et al.,1987; Danesin et al., 2004). However, the mechanism of tyre force generation is represented by empirical on-road tyre models and the road conditions are simplified and reduced to representation by a coefficient of adhesion. This approach should not be extended to off-road vehicles, because the interaction between pneumatic tyres and deformable soil is complex and includes many effects, such as sinkage, multipass and slip sinkage.

An innovation in the field of permanent AWD is the use of visco-lock devices (viscous couplings and visco-lock limited slip differentials) not only to fulfil torque split and transfer function, but also to work as self-controlling devices. Some research work to investigate the contribution of visco-lock devices on $4 \times 4$ vehicle behaviour has been reported, for example in (Hall, 1986; Lugner et al., 1987; Hoeck and Gasch, 1999). However, the transmitted viscous shear torque is introduced, using simple empirical equations or look-up tables, including data fitted from experimental measurements. On the other hand, some mathematical investigations of shear generation in rotary viscous couplings have shed light on the complex sequence of events that result in hump or self-induced torque amplification (Mohan and Ramarao, 2003). Hitherto, there has been a lack of integrated approach for implementation of visco-lock devices in a full vehicle simulation environment, especially for off-road automotive applications.

This paper addresses dynamic performance of permanent AWD off-road vehicles, using visco-lock devices. The basic vehicle dynamics method is reported in (Sharaf et al., 2006; 2007a; 2007b), including the influence of a number of significant parameters (such as mechanical properties of various soils, loading conditions and tyre inflation pressure) on both traction and handling performance. Here, the reported initial approach is extended by inclusion of a detailed tribo-dynamic module for visco-lock devices. Additionally, the tuning process for such units is established in a simulation environment by altering the rheology of the silicone fluid to achieve the required vehicle performance. 


\section{Theoretical Formulation}

\subsection{The Tyre Model}

The employment of a detailed model of any drivetrain system would be meaningless without an equally elaborate representation of the tyre-soil interactions. For this reason, the newly developed $A S^{2} T_{M}$ Soft Soil Tyre Model is used. The model accounts for the pressure-sinkage in the vertical direction, and the shear-tensiondisplacement in the horizontal direction. Both phenomena are particular to off-road tyres and affect the tyre-force generation process to such an extent that typical tyre models for rigid roads cannot be employed for the simulation of the interaction between tyres and soft soils. The main features, limitations, and mathematical representation of the off-road tyre model can be found in many references, for example (Harnisch et al., 2005).

\subsection{The Vehicle Model}

The vehicle is divided into five masses. These are: the vehicle mass (sprung, or body mass concentrated at its centre of gravity) and located above the suspension springs, and four unsprung masses, which represent the assemblies: wheels, axles, and suspensions. The vehicle body is assumed to be rigid, with mass $\left(M_{S}\right)$ and moments and products of inertia. The rigid body has six degrees of freedom, which includes three translations $(U, V, W, x, y, z)$ and three rotations $(p, q, r, \phi, \theta, \psi)$. The wheels are connected to the vehicle body via springs and shock absorbers. It is assumed that each wheel has two degrees of freedom, one for the vertical displacement $\left(Z_{w i}\right)$, and the other for wheel rotation $\left(\omega_{i}\right)$. Thus, the total degrees of freedom are 14 .

According to the SAE recommended frame of reference, these motions are observed relative to the vehicle-fixed local frame of reference, as shown in Figure (1). The vehicle attitude and trajectory through the course of a manoeuvre are defined with respect to a right-handed orthogonal frame of reference, fixed on the ground, referred to as the global frame of reference. This is located directly beneath the vehicle's body- fixed coordinate system at the point, where the manoeuvre has commenced. Another four coordinate systems for the wheels are added to represent each wheel motion independently. Relative transformations are employed to express various states in different frames of reference.

The equations of motion for the non-linear, unsteady motion of the vehicle sprung mass are based on the Newton-Euler formulation for translational and rotational motions. These are derived with respect to the local frame of reference. Simplifications may be carried out by assuming the local frame of reference to be located at the vehicle sprung mass C.G. To further simplify the calculations, symmetry is assumed in the $x-y$ and $y-z$ planes. Thus, the $x-y$ and $y-z$ products of inertia can be neglected. However, symmetry is not assumed in $x-z$ plane, so $\left(I_{x z}\right)$ is included in the angular equations of motion.

The equations of motion of the sprung mass are thus written as follows:

Longitudinal dynamics: $\sum F_{X}=M_{S} \cdot(\dot{U}+W \cdot q-V \cdot r)$ 


$$
\begin{array}{ll}
\text { Lateral dynamics } & : \sum F_{Y}=M_{S} \cdot(\dot{V}+U \cdot r-W \cdot p) \\
\text { Vertical dynamics } & : \sum F_{Z}=M_{S} \cdot(\dot{W}+V \cdot p-U \cdot q) \\
\text { Roll dynamics } & : \sum M_{X}=I_{x x} \cdot \dot{p}-\left(I_{y y}-I_{z z}\right) \cdot q \cdot r-I_{x z}(\dot{r}+p \cdot q) \\
\text { Pitch dynamics } & : \sum M_{Y}=I_{y y} \cdot \dot{q}-\left(I_{z z}-I_{x x}\right) \cdot r \cdot p-I_{x z}\left(r^{2}-p^{2}\right) \\
\text { Yaw dynamics } & : \sum M_{Z}=I_{z z} \cdot \dot{r}-\left(I_{x x}-I_{y y}\right) \cdot p \cdot q-I_{x z} \cdot(\dot{p}-q \cdot r)
\end{array}
$$

$\left(\sum F_{X}\right)$ is the net force, acting on the vehicle body in the longitudinal direction. This results from the tyre forces $\left(\sum F_{x i}\right)$ due to both traction/braking and cornering, transformed from the wheel coordinate system to the bodyfixed system, using the steer-angles. Both aerodynamic and drag resistance due to uneven roads are also taken into account.

$\left(\sum F_{Y}\right)$ is the net lateral force, expressed as a projection of the net tyre forces on the vehicle y-axis, using the steer-angles.

$\left(\sum F_{Z}\right)$ is the net force, affecting the vehicle body in the vertical direction which is calculated as a difference between vehicle body weight and suspension forces. The effect of inclined road surfaces is also taken into consideration.

The unsprung mass dynamics are included by considering each wheel to have a mass $\left(M_{w_{i}}\right)$, connected to the vehicle body via a spring-damper system. All suspension forces are assumed to be vertically directed. The equations of motion of the unsprung masses are given below, considering the vehicle body displacements at the four corners of the vehicle.

$$
\begin{aligned}
& \text { Unsprung mass (1) } \quad: \quad M_{w_{1}} \cdot \ddot{Z}_{w_{1}}=M_{w_{1}} \cdot g+C_{f} \cdot\left(\left(W-\frac{t_{r_{f}}}{2} \cdot p-a \cdot q\right)-\dot{Z}_{w_{1}}\right)+K_{f} \cdot\left(\left(Z-\frac{t_{r_{f}}}{2} \cdot \phi-a \cdot \theta\right)-Z_{w_{1}}\right)+F_{z_{1}} \\
& \text { Unsprung mass (2) } \quad: \quad M_{w_{2}} \cdot \ddot{Z}_{w_{2}}=M_{w_{2}} \cdot g+C_{f} \cdot\left(\left(W+\frac{t_{r_{f}}}{2} \cdot p-a \cdot q\right)-\dot{Z}_{w_{2}}\right)+K_{f} \cdot\left(\left(Z+\frac{t_{r_{f}}}{2} \cdot \phi-a \cdot \theta\right)-Z_{w_{2}}\right)+F_{z_{2}} \\
& \text { Unsprung mass (3) } \quad: \quad M_{w_{3}} \cdot \ddot{Z}_{w_{3}}=M_{w_{3}} \cdot g+C_{r} \cdot\left(\left(W-\frac{t_{r_{r}}}{2} \cdot p+b \cdot q\right)-\dot{Z}_{w_{3}}\right)+K_{r} \cdot\left(\left(Z-\frac{t_{r_{r}}}{2} \cdot \phi+b \cdot \theta\right)-Z_{w_{3}}\right)+F_{z_{3}} \\
& \text { Unsprung mass (4) } \quad: \quad M_{w_{4}} \cdot \ddot{Z}_{w_{4}}=M_{w_{4}} \cdot g+C_{r} \cdot\left(\left(W+\frac{t_{r_{f}}}{2} \cdot p+b \cdot q\right)-\dot{Z}_{w_{4}}\right)+K_{r} \cdot\left(\left(Z+\frac{t_{r_{f}}}{2} \cdot \phi+b \cdot \theta\right)-Z_{w_{4}}\right)+F_{z_{4}}
\end{aligned}
$$

Calculation of the wheel spin velocity $\left(\omega_{i}\right)$ requires the wheel spin acceleration $\left(\dot{\omega}_{i}\right)$, which arises from the driving torque $\left(M_{D_{i}}\right)$, braking torques $\left(M_{B_{i}}\right)$ and the tyre circumferential moments $\left(M_{U_{i}}\right)$, see Figure (1). From the wheel torque balance, the differential equation for the spin degree-of-freedom can be written as follows, where $(i)$ represents the wheel number (1 to 4$)$. 


\subsection{The Drivetrain Model}

The drivetrain model embodies the dynamic characteristics of a typical $4 \times 4$ vehicle including the engine, clutch, a manual gear-box, and three differentials, namely: central (open or locked), front (open) and rear (open) differentials, as well as the transmission elements such as propeller shafts and axles.

The drivetrain model is implemented using a new toolbox called SimDriveline (The MathWorks Inc., 2004-2006), which is part of the Simulink Physical Modelling. With SimDriveline, it is possible to represent a drivetrain system with a simple block diagram. Rotational motion can be initiated in a driveline with actuators while measuring, via sensors, the motions of driveline elements and the torques acting on them. The SimDriveline libraries offer blocks to represent rotating bodies, gearing constraints among the bodies, special dynamic elements such as spring-damper forces, clutches, transmissions, sensors and actuators. The details of the drivetrain model are fully explained in (Sharaf et al., 2006).

For the purpose of the present investigation, a special library is created including custom blocks representing the different mechanical and visco-lock torque distribution devices. In addition to open and mechanically locked ordinary differentials, a mechanical transfer case is modelled to statically split the driving torque from the gearbox between the front and rear axles. The transfer case contains a set of planetary gears (single pinion). Unlike the ordinary open differentials, which equally split torque, a transfer case can statically split torque at different fixed ratios by changing the ratio between the diameters of the planetary sun to ring gears.

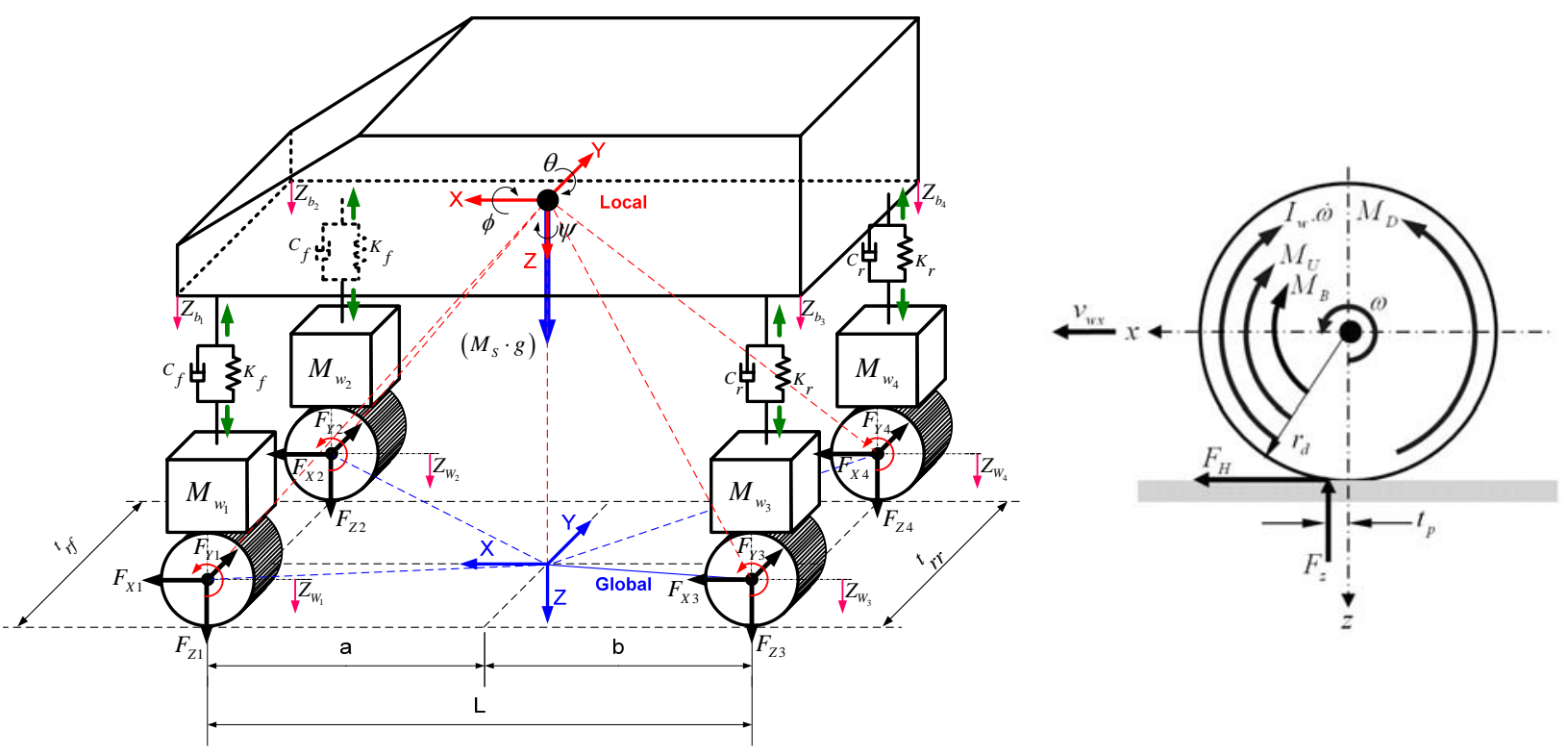

Figure: 1 Free body diagram of the vehicle model 


\subsection{Visco-Lock Device Models}

The viscous coupling unit forms the core of an entire family of visco-lock devices, Figure (2). In general, it can be connected in series between front and rear axles to act as a viscous transmission element (VT), or it can be connected in parallel with an ordinary differential to act as a viscous control element (VC). In a parallel connection, there are two common ways of installing the viscous unit. These are: the shaft-to-carrier and the shaft-to-shaft layouts. In a shaft-to-carrier layout, one set of plates is splined to the differential carrier, whilst the other set of plates is splined to the differential gear on one side which, in turn, is of course splined to its shaft. On the other hand, with a shaft-to-shaft arrangement, the plates are connected alternately, one set to each of the differential gears.

The viscous coupling unit consists of one set of inner plates which is splined to a driving shaft and another set of outer plates, which is then splined to the outer drum, which in turn is rigidly connected to the driven shaft. The plates are separated by a thin film of silicone fluid. The main mechanism for torque transfer is based on the shearing of this fluid film. Therefore, the generated resistive torque of the viscous coupling is dependent on the relative speed of the rotating contacting elements, plate's dimensions and the rheology of the silicone fluid. It should be noted that, generally, there are two modes of viscous coupling operation; one is through the usual viscous shearing action and the other is the self-torque amplification (hump) mode.
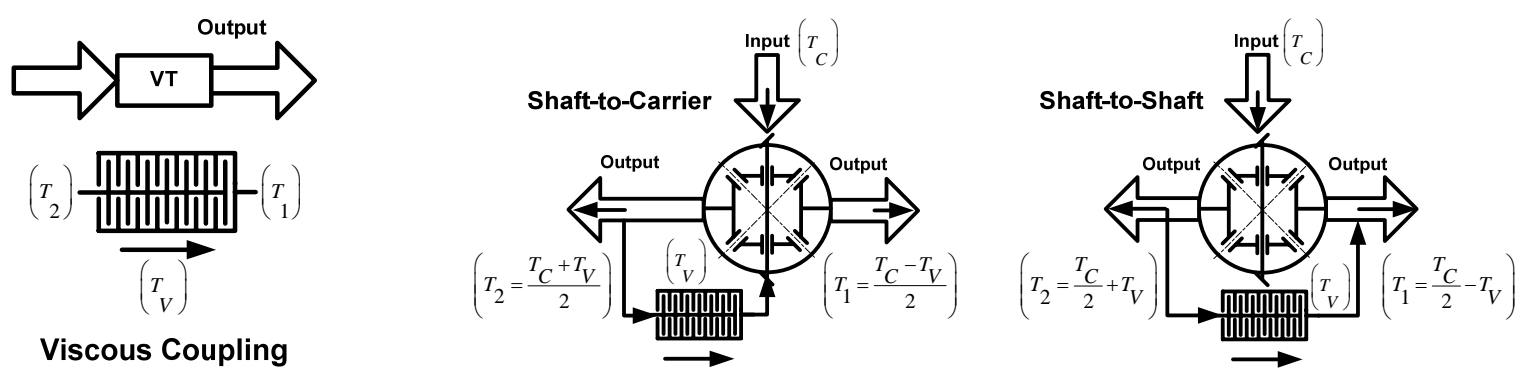

Figure: 2 Structure of Various Types of Visco-Lock Devices

\section{Viscous Shear Mode:}

Assuming a Newtonian fluid and isothermal conditions, the total viscous shear torque $\left(T_{v}\right)$ contributed by one side of the inner plate can be derived from basic principles by integrating the moment due to the shear stress over the active area from the inner plate radius $\left(r_{2}\right)$ to the outer plate radius $\left(r_{1}\right)$ as follows:

Newtonian fluid and isothermal $\quad: T_{V}=\frac{\pi \cdot K_{P} \cdot \rho \cdot v \cdot \omega}{2 \cdot S} \cdot\left(r_{2}^{4}-r_{1}^{4}\right)$

Where; $\left(K_{P}\right)$ is a correction factor to modify the acting area to account for the slots and perforations in the plate structure, $(\rho, v)$ are silicone fluid density and kinematic viscosity respectively. $(\omega)$ is the differential speed between the inner and outer plates, which are separated by a gap $(S)$. However, silicone fluids exhibit pseudo- 
plastic behaviour, i.e. their viscosity decreases with increasing shear strain rate $(\dot{\gamma})$. This non-Newtonian behaviour may be modelled according to the following equation:

Viscosity-shear rate dependency $: v=v_{o} \cdot\left(\frac{\dot{\gamma}}{\dot{\gamma}_{B}}\right)^{m}$

Where $(m)$ is the slope of viscosity-shear rate curve. A correction for viscosity must be carried out by substituting the viscosity given by equation (13) and integrating over the shearing area, which yields the following equation:

Non-Newtonian fluid and isothermal : $T_{V}=\frac{2 \pi \cdot \rho \cdot v_{o}}{\dot{\gamma}_{B}^{m} \cdot(4+m)} \cdot\left(\frac{\omega}{S}\right)^{(1+m)} \cdot\left(r_{2}^{(4+m)}-r_{1}^{(4+m)}\right)$

The work done in shear on the fluid is converted to heat $(Q)$ and raises the temperature of the fluid. If the duration of a test is small compared to the characteristic thermal diffusion time for the system, then the system may be considered to be adiabatic and all the energy may be assumed to go into the core of the viscous coupling. If the instantaneous torque and rotational speed are known, then the effective rate of heat generation may be equated to the shear work done $\left(\frac{d Q}{d t}=T_{V} \cdot \omega\right)$. Consequently, the temperature rise $(\Delta \vartheta)$ can be calculated as follows:

$$
Q=\left(m_{f} \cdot c_{f}+m_{c} \cdot c_{c}\right) \cdot \Delta \vartheta=T_{V} \cdot \omega \cdot \Delta t
$$

During the computation, for each time $\operatorname{step}(\Delta t)$, the temperature rise $(\Delta \theta)$ is calculated and the viscosity at any temperature $\left(v_{\theta}\right)$ is modified according to the following equation; where $(A)$ is an empirical constant.

Viscosity- temperature dependency $: \log \left(v_{\theta}\right)=\log \left(v_{\theta_{0}}\right) \cdot 10^{A \cdot \log \left(\frac{\theta}{\theta_{0}}\right)}$

The calculated viscous shear torque is plotted, Figure (3), for all the derived models during a ramp increase in speed from 0 to $100 \mathrm{rpm}$ in 10 seconds. The non-Newtonian, adiabatic calculation shows good correlation with the experimental results from a number of $10 \mathrm{sec}$ runs up to $100 \mathrm{rpm}$. 

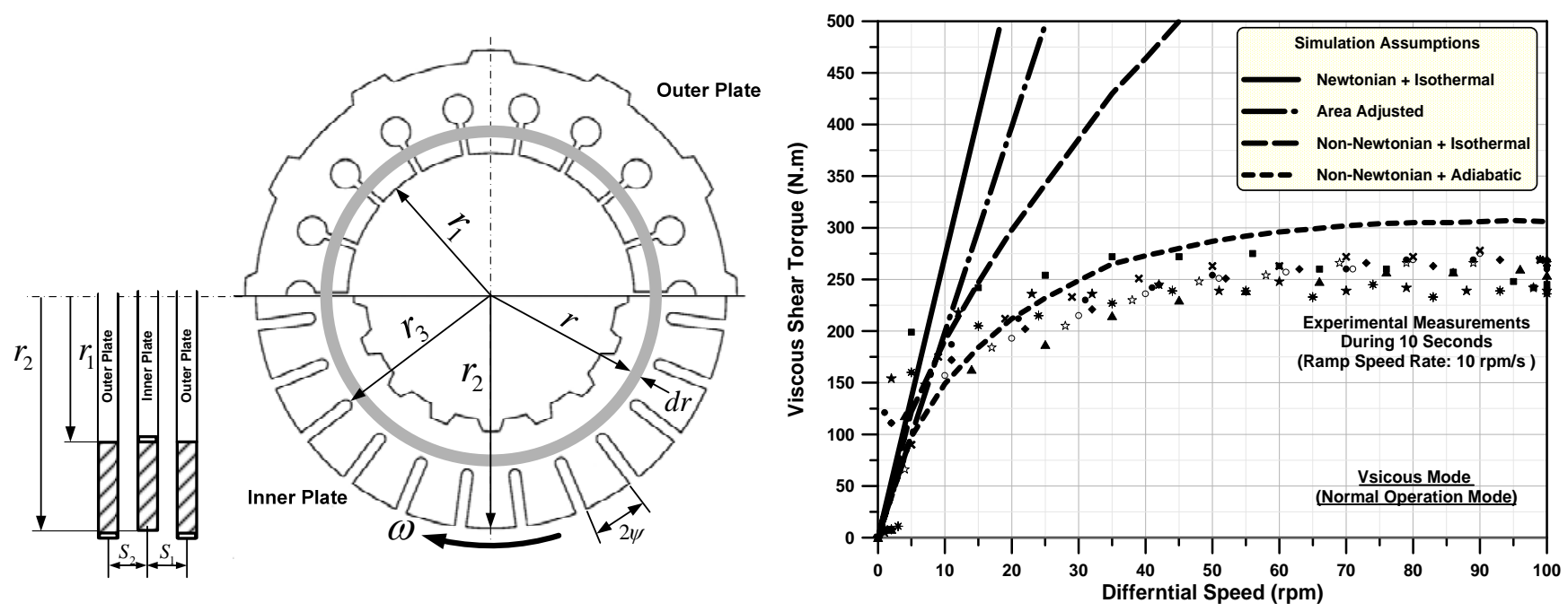

Figure: 3 Viscous Shear Mode (Modelling and Experimental Results)

\section{Self-Torque Amplification (Hump) Mode:}

A peculiarity in the design of rotary viscous coupling is that its plates include slots and perforations. Also the inner plate tabs are produced with an edge (1), the circled numbers are described in Figure (4), which activates the initiation of the well known hump mode. For the aforementioned model, it is assumed that the gap $(S)$ between inner and outer plates remains constant. This assumption may be upheld over short periods of time. It is found that the plates are subjected to an axial force which causes axial deflection of the plates. Due to the resulting change in the gap between the plates, differential shear stress across the inner plate tab creates a twisting moment $\left(M_{t v}\right)$ (2), which tends to twist the tab around its centroid (3). With the twisted shape of the inner plate $\operatorname{tab}\left(\delta_{t v}\right)$ and the differential speed between the inner and outer plate $(U)$, tabs act as a sliding pad bearing, generating a hydrodynamic pressure $\left(P_{1}\right)$ over them which, in turn, further increases the axial force $\left(P_{t}\right)$ (4). The generated hydrodynamic pressures are limited by the bulk pressure $\left(P_{o}\right)$ inside the viscous coupling. At room temperature, the coupling is only partially filled with the silicone fluid. At a certain critical temperature, when all the silicone fluid has expanded to fully fill the voids, the bulk pressure increases (6). Consequently, the hydrodynamic pressure and the net axial force $\left(P_{t}\right)$ increase rapidly until the plates come into contact with each other (5). At this point, a Coulomb friction torque $\left(T_{C}\right)$ is generated, which causes more twist of the inner plate tab (7). The generated Coulomb torque is added the viscous torque and form a sharp increase in torque, known as humping torque $\left(T_{T}\right)$. The mathematical modelling of this sequence of events can be summarized as follows:

Tab twisting moment $\quad: M_{t v}(r)=\int_{-\psi}^{\psi} \int_{r}^{r_{2}}\left(\left[\mu \cdot \frac{d u}{d y}\right]_{2}-\left[\mu \cdot \frac{d u}{d y}\right]_{1}\right) \cdot\left(\frac{t_{i}}{2}\right) \cdot r \cdot d r \cdot d \psi$ 
Tab twisting angle $\quad: \delta=\int_{r_{3}}^{r_{2}} d \delta=\frac{l \cdot t_{i}}{2} \cdot \mu \cdot \omega \cdot\left(\frac{1}{S_{2}}-\frac{1}{S_{1}}\right) \cdot \int_{r_{3}}^{r_{2}} \frac{r \cdot\left(r-r_{3}\right)}{K_{t} \cdot G} d r=\frac{l \cdot t_{i}}{2} \cdot \mu \cdot \omega \cdot\left(\frac{1}{S_{2}}-\frac{1}{S_{1}}\right) \cdot \frac{\left(2 r_{2}^{3}-3 r_{2}^{2} \cdot r_{3}+r_{3}^{3}\right)}{6 K_{t} \cdot G}$

Hydrodynamic pressure : $P_{1}=p_{o} \cdot l+\frac{6 \mu \cdot U \cdot l^{2}}{\left(k_{1}^{2}-1\right) h_{2}^{2}}\left(\ln \left(k_{1}\right)-\frac{2\left(k_{1}-1\right)}{k_{1}+1}\right)$

Net axial force / plate $\quad: P_{t}=\left(P_{1}+P_{2}\right) \cdot L \cdot n_{t a b}$

Coulomb friction torque : $T_{c}=\frac{2}{3} \cdot \pi \cdot \eta \cdot\left(\frac{P_{t}}{\pi \cdot\left(r_{2}^{2}-r_{1}^{2}\right)}\right) \cdot\left(r_{2}{ }^{3}-r_{3}^{3}\right)$

Total transmitted torque : $T_{T}=\left(T_{V}+T_{C}\right) \cdot n_{\text {outer }} \cdot K_{P}$

The change in silicone temperature due to shear and Coulomb effects is calculated by making some simplifying assumptions of lumped-mass and one-dimensional thermal conduction model. The generated viscous shear and the Coulomb friction work done by the rotating plates are converted into heat $(Q)$, which is calculated as follows:

$$
\frac{d Q}{d t}=\left(T_{V}+T_{C}\right) \cdot \omega
$$

It is assumed that the viscous coupling core, consisting of the fluid and the plates, is at a homogenous temperature $\left(\theta_{f}\right)$, due to their intimate contact and stirring motion. Heat is conveyed from the core at $\left(\theta_{f}\right)$, through the housing by conduction. The energy conducted from the viscous coupling core into the housing $\left(Q_{1}\right)$ can be calculated as follows, where $\left[\frac{k A}{\Delta x}\right]_{S}$ is the equivalent conduction parameter through the housing.

$$
\frac{d Q_{1}}{d t}=\left[\frac{k A}{\Delta x}\right]_{S} \cdot\left(\theta_{f}-\theta_{s}\right)
$$

Heat is dissipated from the outside housing surface at $\left(\theta_{s}\right)$, by convection to the surrounding air at $\left(\theta_{a}\right)$. The energy convected by the air from the housing's outside surface $\left(Q_{2}\right)$ can be calculated, where $[h \cdot A]_{S}$ is the corresponding convection parameter from the housing's outer surface:

$$
\frac{d Q_{2}}{d t}=[h \cdot A]_{S} \cdot\left(\theta_{s}-\theta_{a}\right)
$$

Two other relations can also be obtained from the heat balance from core to the housing and from the housing to air as follows:

$$
\frac{d Q}{d t}-\frac{d Q_{1}}{d t}=[m c]_{C} \cdot \frac{d \theta_{f}}{d t}
$$




$$
\frac{d Q_{1}}{d t}-\frac{d Q_{2}}{d t}=[m c]_{S} \cdot \frac{d \theta_{s}}{d t}
$$

The parameters $(\mathrm{mc})_{C}$ and $(\mathrm{mc})_{S}$ denote the equivalent thermal masses for the viscous coupling core and the steel housing respectively. During the simulation, Equations (23-27) are solved numerically to obtain the fluid and housing temperatures. Figure (4) shows the mathematical model, as well as some experimental results for the self-torque ampification (hump) mode.
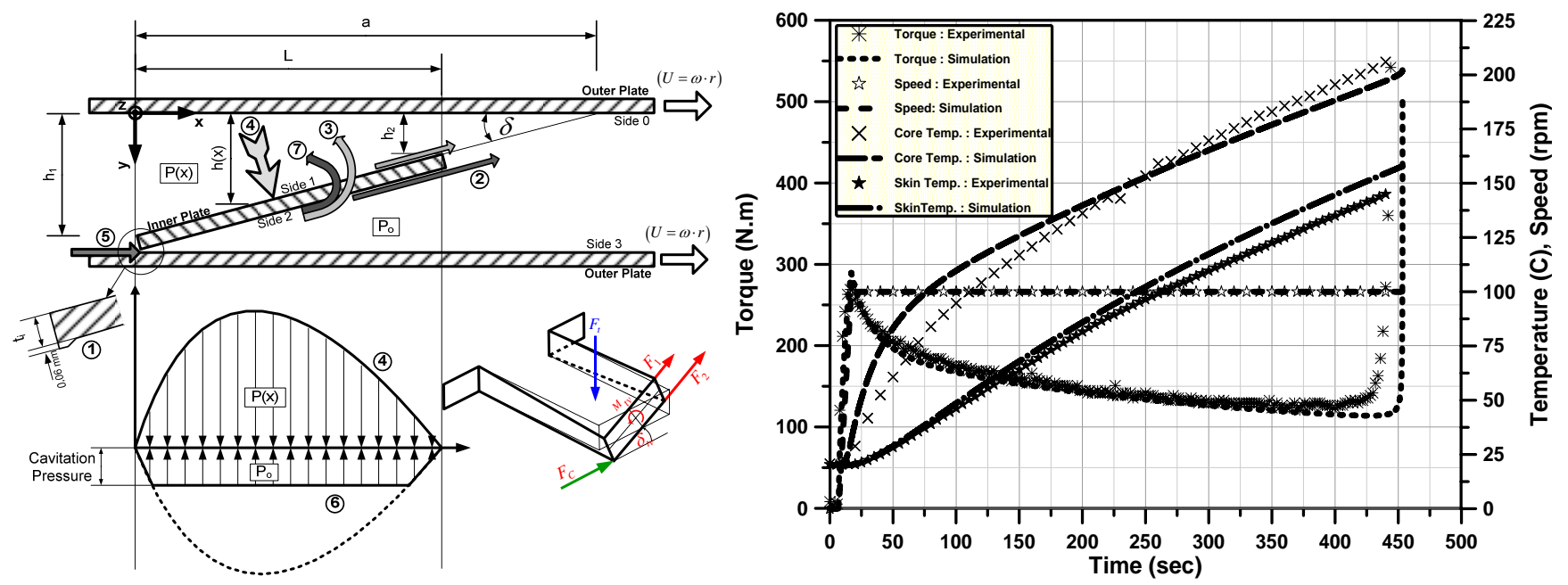

Figure : 4 Self-Torque Amplification Mode (Model and Experimental Results)

\section{NUMERICAL SIMULATION}

Traction Criterion: One of the most important criteria to judge the traction capabilities of an off-road-vehicle is the drawbar pull performance, which describes the actual tractive force at the towing device. The procedure involves adding a slowly growing towing capacity on the vehicle, driven at a low constant speed of $15 \mathrm{~km} / \mathrm{h}$ in the lowest gear. The test is terminated, when full wheel slip is considered to have reached. The advantage of this test is that it provides a complete picture of traction performance over the entire range of tyre longitudinal slip. To keep the vehicle speed constant, a PID controller is used, which acts as the throttle pedal to control the engine torque. As the towing load increases, the engine torque also increases, as well as the tractive force. The relationship between the tractive force and longitudinal slip for each tyre can then be plotted, Figure (5).

Another criterion is based on that proposed by Wong (1970) and Wong et al. (2000), in which the performance of a cross-country vehicle can be evaluated in terms of its tractive efficiency. This approach is extended here to examine traction characteristics of AWD vehicles, fitted with different torque distribution devices. The tractive efficiency $\left(\eta_{d}\right)$ of a wheeled vehicle under constant speed, straight turning conditions on horizontal ground may be expressed as follows:

Tractive efficiency $\quad: \eta_{d}=\eta_{m} \cdot \eta_{s} \cdot \eta_{t}$ 
$\left(\eta_{m}\right)$ : represents the efficiency which is a measure of losses incurred in transforming the available driving torque at the driven wheels $\left(M_{d i}\right)$ to the successfully pull at the drawbar $\left(F_{d}\right)$.

Motion efficiency $\quad: \eta_{m}=\frac{\left(\sum_{i=1}^{4} F_{x i}-\sum R\right)}{\left(\sum_{i=1}^{4} \frac{M_{d i}}{r_{d i}}\right)}$

$\left(\eta_{s}\right)$ : represents the slip efficiency, which characterizes the power losses and also the reduction in forward speed of the vehicle due to slip of the driven wheels. This part of the power dissipates through the sliding of the tyre relative to the terrain surface and internal shearing of terrain material between the tyre lugs. The slip efficiency not only affects drawbar power, but also closely relates to tyre wear. Usually, slip is a major source of power loss during the operation in the field. In general, the slip efficiency can be determined from the ratio of power loss due to slip to the power available at the driven wheel.

Slip efficiency $\quad: \eta_{S}=1-\left(\frac{i_{f} \cdot M_{d f} \cdot \omega_{f}+i_{r} \cdot M_{d r} \cdot \omega_{r}}{M_{d f} \cdot \omega_{f}+M_{d r} \cdot \omega_{r}}\right)$

$\left(\eta_{t}\right)$ : represents the efficiency of the transmission, which characterizes the losses in power from the engine to the driven wheels. It can be given as follows:

Transmission efficiency : $\eta_{t}=\frac{\left(\sum_{i=1}^{4} M_{d i} \cdot \omega_{i}\right)}{\left(M_{e} \cdot \omega_{e}\right)}$

Figure (5), shows the variation of efficiency, longitudinal slip with drawbar pull. The simulation is carried out for a rigid-drive $4 \times 4$ vehicle on clay and loam soil, see table (1). It should be noted that motion efficiency reflects the ability of the soil (in terms of shear and sinkage properties) to support the thrust force, while slip efficiency reflects the utilization of the distributed torque to propel the vehicle forward. It is clear that, for the same concept driveline, due to the higher shearing strengths and lower sinkage properties of clay soil, higher maximum values of drawbar pull and the tractive efficiency can be observed.

Table: 1 Soil mechanical properties

\begin{tabular}{|c|c|c|c|c|c|}
\hline Soil & $\begin{array}{c}\text { Cohesive module of } \\
\text { deformation }\left(N / \mathrm{cm}^{n+1}\right)\end{array}$ & $\begin{array}{c}\text { Frictional module of } \\
\text { deformation }\left(N / \mathrm{cm}^{n+2}\right)\end{array}$ & $\begin{array}{c}\text { Sinkage } \\
\text { exponent } \\
(--)\end{array}$ & $\begin{array}{c}\text { Cohesion } \\
\left(\mathrm{N} / \mathrm{cm}^{2}\right)\end{array}$ & $\begin{array}{c}\text { Angle of internal } \\
\text { friction }\left(^{\circ}\right)\end{array}$ \\
\hline Clay & 35 & 30 & 0.18 & 3.5 & 18 \\
\hline Loam & 18 & 6.0 & 0.50 & 2.5 & 25 \\
\hline
\end{tabular}



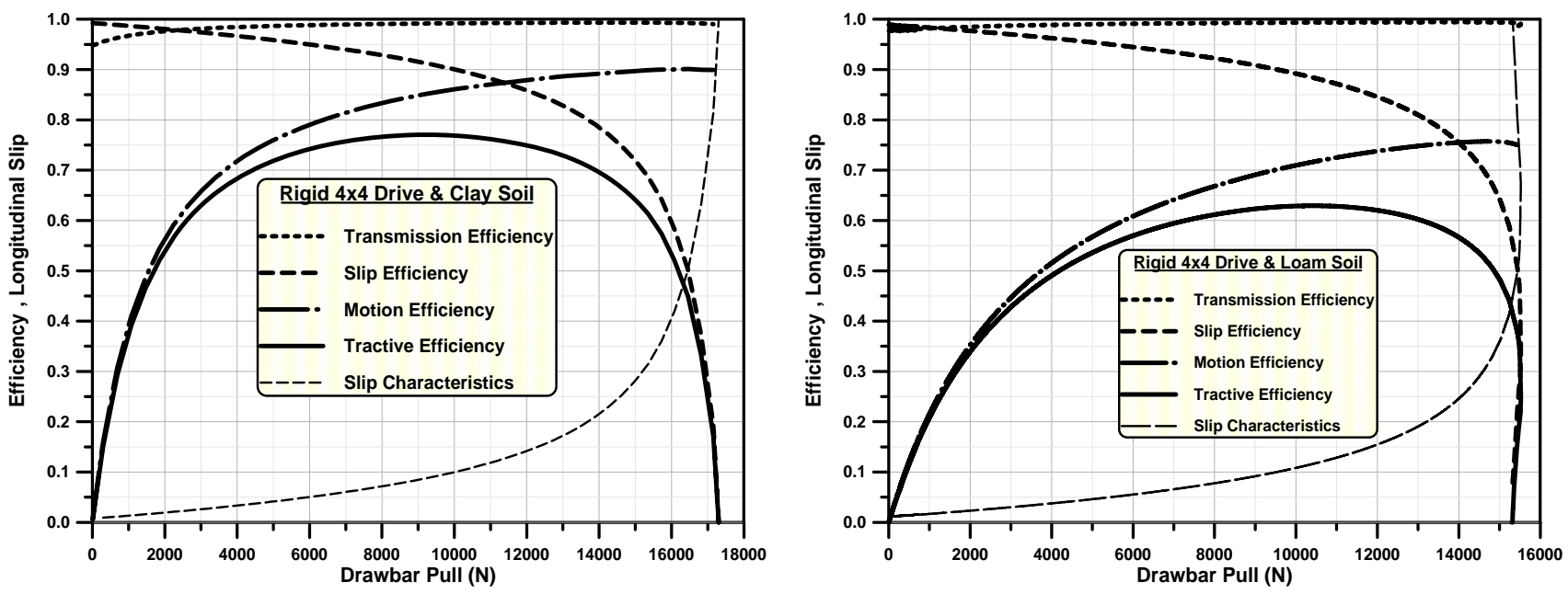

Figure : 5 Variation of Tractive Efficiency with Drawbar Pull

Handling Criterion: A typical off-road AWD vehicle with a ramp-steer manoeuvre (at a constant forward speed of $75 \mathrm{Km} / \mathrm{h}$ ) is considered to assess its handling performance. The steer-angle is increased slowly, whilst driving on a deformable clay soil. The vehicle's response in terms of lateral acceleration is calculated and plotted against steer angle in order to obtain a picture of its handling performance (Wong, 2001). It should be noted that the vehicle is considered to understeer when the slope of the resulting curve is greater than that for the neutral steering case, and to oversteer when the slope is less than the same.

\section{RESULTS AND ANALYSIS}

With regard to the aforementioned criteria, both the traction capability and the directional stability of a typical $4 \times 4$ vehicle are investigated over deformable clay soil. The vehicle's main design parameters are kept the same as before, except for the way torque is distributed between the axles. The inflation pressure is assumed to be 1 bar for all tyres. The weight distribution between front and rear axle is (40:60\%) respectively. Simulation results of visco-lock devices include viscous coupling and a visco-lock differential. These are ploted and compared with the ordinary mechanical devices such as a differential (open/locked), as well as the transfer case with a mechanically biased torque.

\subsection{Different Drivetrain configurations:}

Before discussing the influence of torque distribution devices on the performance of a $4 \times 4$ off-road vehicle, it is useful to introduce the significant role of static load distribution between the front and rear axles. In general, when the axle load increases, both the ground pressure and tyre contact length increase accordingly. Consequently, the maximum soil shear strength and thus the circumferential force is enhanced (circumferential force: resulting from the Integration of local shear stress over the tyre-soil contact area). This increases the ability of the tyres to develop larger tractive forces without causing excessive slip (tractive forces: the horizontal component of the shear stress integral over the contact area). On the other hand, when the axle weight is increased, both the tyre sinkage and rolling resistance also increase. 
Handling characteristics are affected by sinkage due to additional lateral forces generated at the tyre sidewalls. At higher sinkage, significant tyre sidewall forces may occur, which can be explained by the soil cutting theory, (Wong, 1989). According to this theory a stress field occurs in the soil, based on passive soil failure, which is developed using the Mohr's circle technique. This additional lateral force is determined by integrating the passive soil pressure over the tyre sidewall for a given sinkage distribution of the tyres. Generally, the reference vehicle has more weight on its rear axle, and due to these effects, the resulting equivalent cornering stiffness is higher than that developed at the front axle. Consequently, the under-steer coefficient is increased and the vehicle becomes more under-steering with an increased turning radius and a reduced yaw velocity.

Open central-differential, (O-O-O): The main characteristic of this type of drivetrain is that the ratio of angular velocity of the front wheels to that of the rear wheels may vary depending on the operating conditions, but the ratio of the torque distribution between the front and rear wheels is invariable and limited by the lowest traction side (carrying the least weight). Therefore, drive-train torsional wind-up never occurs under any conditions. However, both the maximum drawbar pull and the tractive efficiency still depend on the slips of both front and rear wheels and will only be high if these are equal. In order to achieve high operational efficiency, the weight distribution and other factors must be carefully controlled. For equal torque distribution (inherent of open differential) and dynamic radii of tyres (assumed), the rear axle-tyres are subjected to higher rolling resistance due to higher vertical weight and sinkage. As a result, the net tractive force and thus the longitudinal slip at the rear axle-tyres will be lower than those developed at the front axle-tyres. Consequently, the generated lateral forces at the rear axle will be higher than those at the front axle. On the other hand, the lateral load transfer from inwards to outwards during cornering causes a considerable increase of the tractive force at the inward tyres. The combined effect results in a more under-steering, especially at high lateral accelerations, see Figure (6).

Locked central-differential, (O-L-O): The main characteristic of this type of drivetrain is that the ratio of angular velocity of the front wheels to that of the rear wheels is invariable, but the ratio of the torque distribution between the front and rear wheels may vary depending on operating conditions. Under the condition of equal dynamic tyre radii for the front and rear tyres, they are forced to rotate at the same driving speed, thus the slip of all tyres become equal and regulated by that of the tyre with most traction. Therfore, the slip values at all four corners are automatically adjusted in favour of traction and the performance is no longer affected by the weight distribution.

However, under given steering conditions, the kinematics of the vehicle require that the front and rear wheels follow different paths with different translational speeds. In this case, tractive slip at the front will reduce and skidding might occur in extreme cases, with the subsequent generation of braking forces at the front. On the other hand, the rear wheels slip, generating a forward thrust. Under these circumstances, torsional wind-up in transmission occurs, resulting in premature failure of the driveline components and/or excessive wheel slippage depending on tyre-soil conditions (Wong, 2001).

The rear axle with a larger weight and, therefore, relatively higher shear strength is able to develop a larger driving torque than the front axle. The slip at the front is limited by the slip at the rear and the front tyres improve their potential of lateral force generation. This shifts the handling behaviour towards less understeer, when compared to that achieved by the open central differential configuration. 

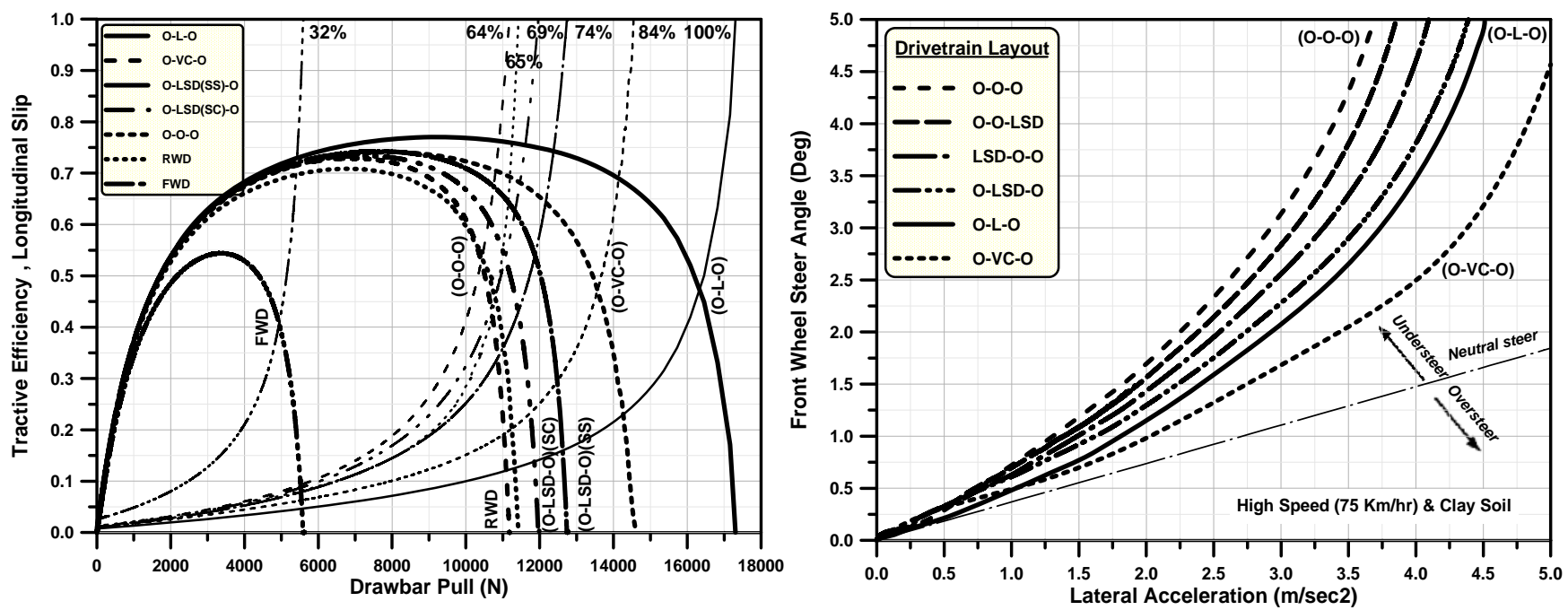

Figure 6: Comparison between Different Drivetrain Configurations

Visco-lock devices: The common feature of such devices is that the torque cannot be transmitted unless there is a speed difference between the input and output shafts. Therefore, these are termed speed sensitive devices. In other words, visco-lock devices act as a passive traction control system to regulate torque distribution between axles according to the speed difference (or slip) between them. If the speed difference (or slip) between axles increases, visco-lock devices bias (send) more torque to the side with a lower speed (front axle). The effect is, therefore, to deliberately introduce a ratio (smaller than unity) of the theoretical speed of the front wheel to that of the rear. This ratio can be tuned or optimised according to the viscous unit design parameters (as described later) to meet the required characteristics. It should be noted that, the effect of a viscous control unit at the central differential, shaft-to-shaft (O-SS-O) or shaft-to-carrier (O-SC-O), is considerably softer than that of a viscous coupling transmission (O-VC-O) for direct torque transfer. However, even rather soft characteristics result in a substantial improvement in traction performance compared with the ordinary open central differential configuration. The handling characteristics provided by visco-lock devices depend on the amount of transmitted torque. However, because there is no rigid connection between the axles (like viscous transmission) the tyres are still free to rotate with different velocities, so the problem of drive-train torsional wind-up is minimized.

It should be noted that, for a given speed difference, the shaft-to-shaft layout exhibits approximately three times the locking torque of the shaft-to-carrier design. It is, therefore, this represents the preferred option for applications in which the space is available and high torque is to be transmitted.

\subsection{Static Split Ratio of Driving Torque Distribution:}

For the purpose of this analysis, a transfer case is used to statically split the driving torque at different fixed ratios. The results of the computations show that, torque distribution between front and rear axle affects the tractive efficiency (particularly slip efficiency) of a 4WD vehicle considerably, see Figure (7). A slight variation in torque distribution causes considerable changes in the tractive efficiency, as well as the handling characteristics. 
Since the reference vehicle has a greater weight on the rear axle, it is obvious that in order to improve the tractive efficiency, the driving torque should also be distributed in a matching manner according to the weight distribution. However, in reality, it is unacceptable to design the vehicle with a fixed scenario of weight distribution between the axles, as both static and dynamic variations in weight distribution would alter the optimum value of torque distribution between the axles.
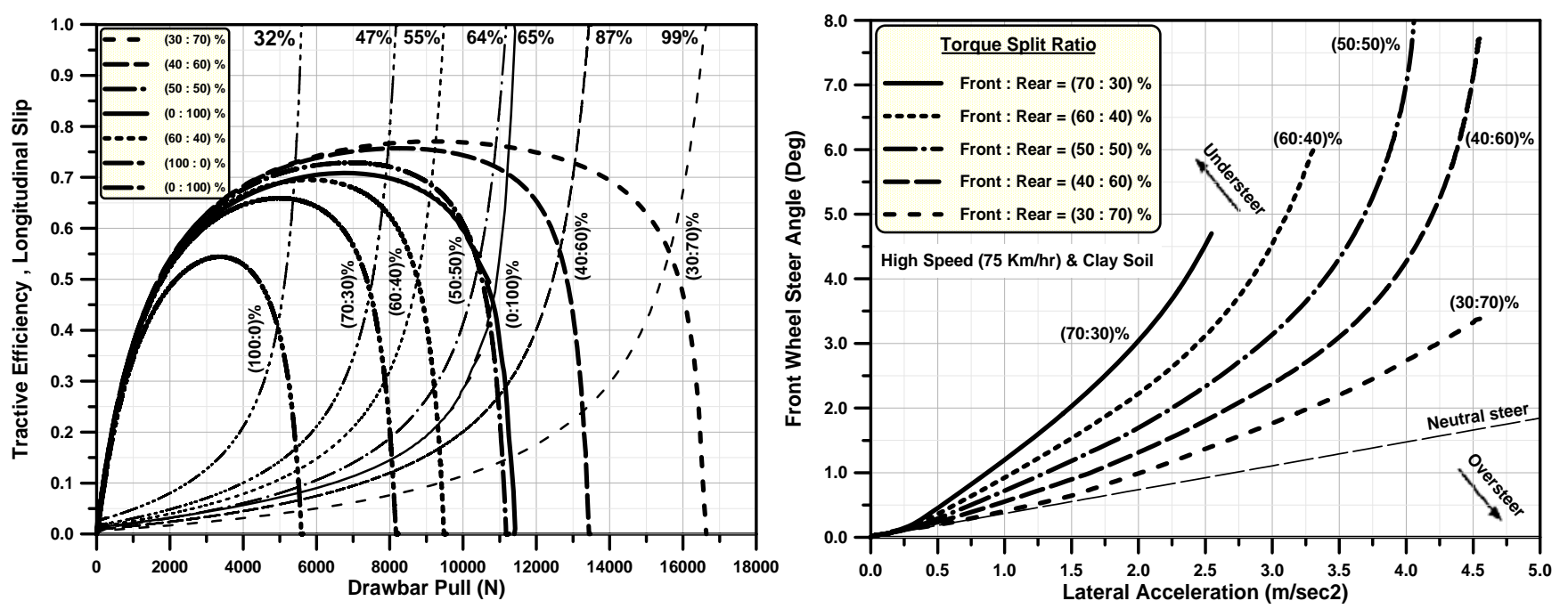

Figure 7: Static Ratio of Driving Torque Distribution between Front and Rear Axle

The above theoretical analysis leads to the conclusion that in order to achieve the maximum efficiency, the important issue in the design and operation of a $4 \mathrm{WD}$ vehicle is to match the driving torque distribution with the weight distribution and with the terrain conditions, so that the slip of the front and rear wheels are close under a wide range of operating conditions. It should be pointed out that, the inefficient distribution of the driving torque not only wastes the power, but can also cause excessive tyre wear. The importance of the analysis of the effect of static distribution of driving torque is that it improves understanding and aids the optimisation of visco-lock devices for traction.

From a handling performance view point, biasing more torque to the rear axle would reduce the longitudinal slip at the front and, consequently, increase the lateral force generating potential at the front. At the same time, the counteracting side force at the rear would be reduced. The additional yaw moment shifts the handing characteristics towards oversteer, a fact which in turn reduces the stability and controllability of the vehicle. Generally, In order to optimise vehicle performance, the ratio of torque distribution between the front and rear axles must be carefully controlled in order to guarantee not only higher traction, but also an acceptable level of controllability and stability.

\subsection{Visco-lock device Tuning:}

Visco-lock devices are designed not only to transmit torque, but also to control its distribution. The transmitted torque must satisfy specific requirements for vehicle performance. Torque characteristics depend on the fluid 
rheology, number of plate pairs, the gap between them and the fluid filling percentage. However, because these devices act as passive control systems, they require tuning (optimisation) before installation into the drive-train system. In reality, this process is carried out by empirically changing the silicone fluid properties in a trial and error approach, which is time consuming and expensive. For the purpose of this investigation, different silicone fluids ( $A, B, C$, and D) with different rheological properties, in terms of kinematic viscosity, as well as shear and thermal properties are used. The silicone fluids can be distinguished according to their kinematic viscosity as follows: (Fluid A: $1.0 \mathrm{~m}^{2} / \mathrm{s}$ ), (Fluid B: $0.1 \mathrm{~m}^{2} / \mathrm{s}$ ), (fluid C: $0.01 \mathrm{~m}^{2} / \mathrm{s}$ ), and (Fluid D: $0.001 \mathrm{~m}^{2} / \mathrm{s}$ ).
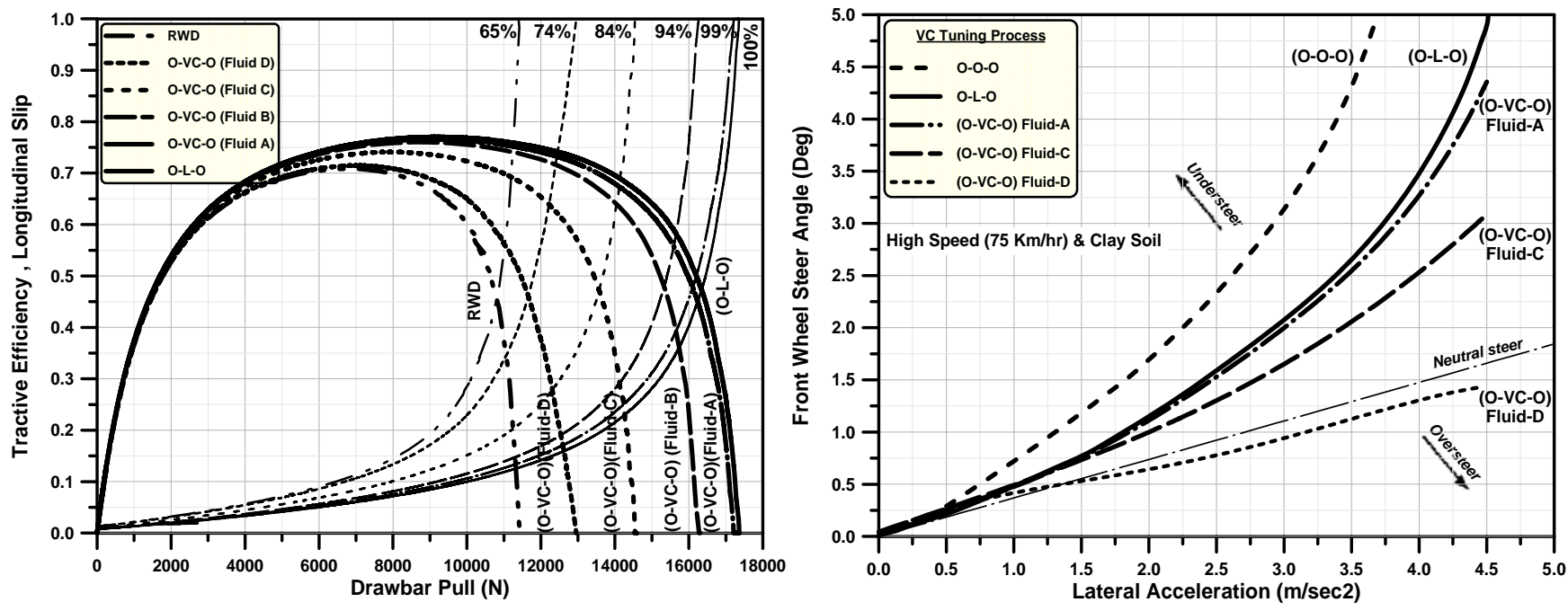

Figure 8: Tuning of Viscous Coupling Unit by changing Silicone Fluid Rheology
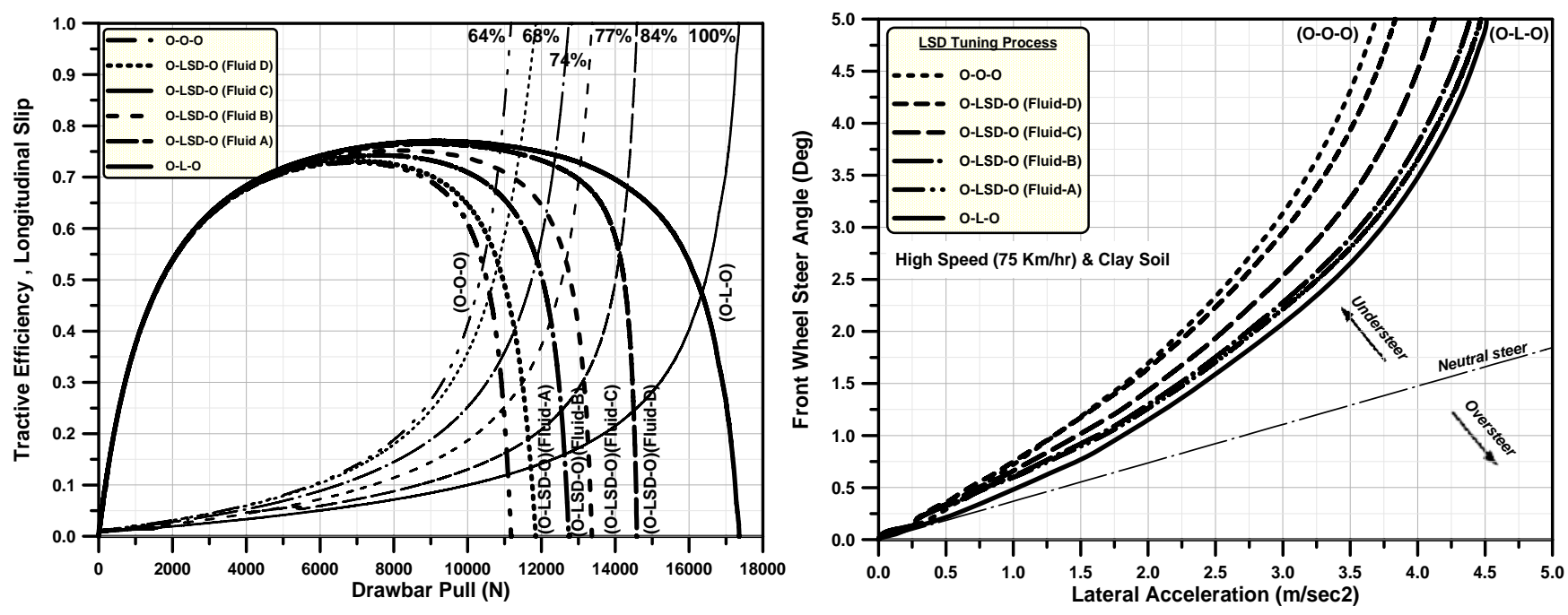

Figure 9: Tuning of Visco-Controlled Differential (Shaft-to-Shaft) Unit by changing Silicone Fluid Rheology

Figures (8-9), show vehicle performance using viscous coupling between the axles, as well as a visco-controlled central differential, tuned using different silicone fluid properties. If the viscous unit is assumed to have a torque 
capacity factor, $\mathrm{K},\left(\frac{N \cdot \mathrm{m}}{\mathrm{rad} / \mathrm{s}}\right)$ at given operating conditions with rotational speed difference $(\Delta \omega)$, the torque bias ratio can be expressed as follows, see figure (2):

$$
\text { Torque Bias Ratio }=\left|T_{2}-T_{1}\right|=K \cdot \Delta \omega
$$

Using a silicone fluid with a higher viscosity (for example, fluid A) makes the unit stiffer with a higher torque capacity factor. This enables larger torques to be transmitted, and thus, the controllability of variables such as rotational speed and slip difference between front and rear axle would be reduced.

It should be noted that, the way viscous coupling is installed in the drivetrain depends on the static ratio of weight distribution between axles. As the reference vehicle carries more weight on the rear axle, the primary drive is to the rear axle and the secondary drive axle via the coupling to the front axle.

This leads to a conclusion that, for viscous coupling (VC), a higher torque capacity factor would increase the locking effect of the unit and set the vehicle performance towards the rigid $4 \times 4$ coupling (O-L-O) characteristics, while a lower torque capacity factor would shift the vehicle performance towards the rear wheel drive (RWD) characteristics.

For the visco-controlled differential (LSD), higher torque capacity factor shifts the vehicle performance towards the rigid $4 \times 4$ coupling (O-L-O) characteristics, while a lower torque capacity factor shifts the vehicle performance towards the open central differential (O-O-O) characteristics.

\section{CONCLUSIONS}

A comprehensive numerical approach to fully implement detailed visco-lock devices in a full vehicle simulation environment is carried out. The integration of all modules results in a multi-physics platform which combines the dynamics of a $4 \times 4$ drive-train system with the vehicle body dynamics, as well as the terra-mechanical phenomena between tyres and deformable soils. Both traction and handling characteristics are examined for various types of drive-train configurations, as well as different scenarios of torque distribution between the front and rear axles, including mechanical and visco-lock devices.

The investigation shows that, vehicle weight distribution is a crucial parameter, which must be taken into account during the optimisation process of AWD off-road vehicle performance. For a given ratio of weight distribution, except for the locked centre differential configuration, the traction capabilities are adversely affected. In order to achieve the maximum tractive efficiency, the driving torque should be distributed to match the weight distribution between the front and rear axles in a manner as to minimize the slip difference between them. In the case that, more torque should be sent to the rear axle, a conflict with the vehicle stability would occur and handling would 
tend to oversteer. For mechanical torque distribution devices, a fixed ratio of torque bias can be carefully selected by appropriately setting the gearing design. On the other hand, for visco-lock devices this torque bias ratio can be tuned-up by carefully selecting the silicone fluid rheological parameters.

The results show that, using fully parameterised physical models of visco-lock devices, the optimisation between traction performance and handling characteristic can be achieved within a virtual prototyping environment. Consequently, the simulation model should prove useful to the manufacturers of AWD off-road automotive applications in the determination of the gearing/coupling method, which would produce the characteristics best suited to a proposed vehicle.

Hitherto, the behaviour of the visco-lock devices has been validated using an experimental test-rig. In terms of the vehicle dynamics model, validation has been carried out in on-road mode of operation and simulation results have shown good agreement with experimental measurements performed using a passenger car. However, it has not yet been possible to assess the accuracy of the off-road simulation as a whole. Some of the difficulties involved include the requirement of soil and off-road tyre parameters identification, as well as repeatability problems related to driving over macro- and microscopically rough surfaces. Hence, the validation of the off-road simulation will form the basis of future work.

\section{ACKNOWLEDGMENTS}

The authors wish to express their gratitude to the Egyptian Military Attache's Office for the financial support extended to this research project.

\section{REFERENCES}

Danesin, D., Girardin, C., Sorniotti, A., Morgando, A. and Velardocchia, M. (2004) 'Driveline layout influence on four wheel drive dynamics', SAE Technical Paper Series No. 2004-01-0860.

Hall, L. C. (1986) 'The influence of limited slip differential on torque distribution and steady state handling of four-wheel derive military vehicles', Proceedings of IMechE International Conformance on All-Wheel Drive, C05/86, pp. 595-66, London, U.K.

Harnisch, C., Lach, B., Jakobs, R., Troulis, M. and Nehls, O. (2005) 'A New tyre-soil interaction model for vehicle simulation on deformable ground', Vehicle System Dynamics, Vol. 43, Supplement, pp. 384 - 394.

Hoeck, M. and Gasch, C. (1999) 'The influence of various 4WD driveline configurations on handling and traction on low friction surfaces', SAE Paper No. 1999-01-0743.

Lugner, P. Lanzer, H. and Bösch, P. (1987) '4 wheel drive with visco computer coupling elements', Proceedings of the $10^{\text {th }}$ IAVSD Symposium, pp. 239-251. 
Maretzke, J. and Richter, B. (1986) 'Direction control of 4WD passenger cars-A study by computer simulation', SAE Technical Paper Series No. 861370.

Mohan, S.K. and Williams, R.C. (1995) 'A survey of 4WD traction control systems and strategies', SAE Technical Paper Series No. 952644, pp. 59-76.

Mohan, S.K. and Ramarao, B.V. (2003) 'A comprehensive study of self-induced torque amplification in rotary viscous couplings', Transactions of the ASME, Journal of Tribology, Vol. 125, pp.110-120.

Sharaf, A.M., Mavros, G., Rahnejat, H. and King, P.D. (2006) 'Multi-physics modelling approach In all terrain vehicle longitudinal dynamics', Paper IMECE2006-13578, Proceedings of IMECE06, ASME International Mechanical Engineering Congress and Exposition, Chicago, Illinois, USA.

Sharaf, A.M., Mavros, G., Rahnejat, H., King, P.D. and Mohan, S.K. (2007a) 'Direction control and stability of AWD off-road vehicles fitted with visco-lock devices', Poster paper, $20^{\text {th }}$ International Symposium: Dynamics of Vehicles on Roads and Tracks, Berkeley, California, USA.

Sharaf, A.M., Rahnejat, H. and King, P.D. (2007b) 'Analysis of handling characteristics of all-wheel drive offroad vehicles', Int. J. Heavy Vehicle Systems, Vol. x, No. x, pp. xxx-xxx (in press)

Tani, M., Yuasa, H. and Isoda, K. (1987) 'Controllability and stability of various types of four wheel drive cars', SAE Technical Paper Series No. 870542.

The MathWorks Inc. (2004-2006) 'SimDriveline for use with Simulink User's Guide Version 1', viewed 15 April 2007, http:www.mathworks.com.

Wong, J.Y. (1970) 'Optimization of the tractive performance of four wheel-drive off-road vehicles', SAE Paper No. 700723 , Vol. 79 , pp. 2238-2245.

Wong, J.Y. (1989) 'Terramechanics and Off-Road Vehicles', Elsevier Science, New York, NY 10010, USA.

Wong, J.Y., Zhao, Z., McLaughlin, J.N.B. and Burtt, S. (2000) 'Optimization of the performance of four-wheeldrive tractors: correlation between analytical prediction and experimental data', SAE Paper No. 2000-012596.

Wong, J.Y. (2001) 'Theory of ground vehicles', 3rd ed., John Wiley, New York. 